
Horticultura Brasileira 27: 017-022.

\title{
Índice SPAD e produção de batata, em duas épocas de plantio, em função de doses de nitrogênio ${ }^{1}$
}

\author{
Marcelo CC Silva; Paulo CR Fontes; Glauco V Miranda \\ UFV-DFT, 36570-000 Viçosa-MG; mdecastro70@yahoo.com.br; pacerefo@ufv.br
}

\begin{abstract}
RESUMO
Objetivou-se determinar o valor do nível crítico do índice SPAD (NC) no folíolo terminal da quarta folha da batata (Solanum tuberosum L.) e a dose de nitrogênio $(\mathrm{N})$ para maximizar a produtividade da 'Monalisa', em duas épocas de plantio, seca e águas. O experimento foi realizado na UFV em um solo Podzólico Vermelho-amarelo. Foram avaliadas cinco doses de $\mathrm{N}$ em pré-plantio $(0 ; 50 ; 100 ; 200$ e 300 $\left.\mathrm{kg} \mathrm{ha}^{-1}\right)$ aplicadas no sulco, e quatro doses de $\mathrm{N}$ em cobertura $(0 ; 100$; 200 e $300 \mathrm{~kg} \mathrm{ha}^{-1}$ ), via sulfato de amônio. O delineamento foi de blocos casualizados, com parcelas subdivididas, e quatro repetições. Nas parcelas tinham-se as doses em pré-plantio e nas subparcelas as de cobertura. Aos 21 dias após a emergência, antes da adubação em cobertura, foi determinado o NC. Nas épocas da seca e águas, os valores de NC foram 42,2 e 35,2. Esses valores estavam associados à dose de $\mathrm{N}$ em pré-plantio (PP) que propiciou a maior produção comercial de tubérculos de batata, 39,88 e 44,46 t ha ${ }^{-1}$, respectivamente. Na época seca, somente a aplicação de $\mathrm{N}$ em PP proporcionou incrementos na produção sendo a máxima produção comercial de tubérculos obtidos com 189,98 $\mathrm{kg} \mathrm{ha}^{-1}$ de $\mathrm{N}$. Na época das águas, deve-se realizar aplicação de N em PP e em cobertura, com a dose total de $255,85 \mathrm{~kg} \mathrm{ha}^{-1} \mathrm{de} \mathrm{N}$, da qual $20 \%$ aplicada em pré-plantio e o restante em cobertura na época da amontoa.
\end{abstract}

Palavras-chave: Solanum tuberosum L., épocas de plantio, adubação, clorofilômetro.

\begin{abstract}
SPAD index and potato yield, in two planting periods, depending on nitrogen rates

The SPAD index critical value (NC) in the terminal leaflet of the fourth potato plant leaf (Solanum tuberosum L.) was determined and, the nitrogen $(\mathrm{N})$ rate to obtain the maximum 'Monalisa' yield, at dry and wet seasons. The experiment was carried out in Viçosa, Minas Gerais State, Brazil in a soil Podzolic red-yellow. Five preplanting nitrogen rates were evaluated $\left(0 ; 50 ; 100 ; 200\right.$ and $300 \mathrm{~kg} \mathrm{ha}^{-}$ $\left.{ }^{1}\right)$ applied in the planting furrow with four sidedress $\mathrm{N}$ rates $(0 ; 100$; 200 and $300 \mathrm{~kg} \mathrm{ha}^{-1}$ ) using ammonium sulfate as the $\mathrm{N}$ source. The experiment was installed in a randomized complete block design with split-plots and four repetitions. In the plots the rates of $\mathrm{N}$ were applied in pre-planting, and in the split-plots in sidedress. 21 days after plant emergence, immediately before the $\mathrm{N}$ fertilizer sidedressing, SPAD NC was determined. At dry and wet seasons, SPAD NC were 42.2 and 35.2. These values were associated with the pre-planting $\mathrm{N}$ rates which led to the highest commercial tuber yields, 39.88 and $44.46 \mathrm{t} \mathrm{ha}^{-1}$, respectively. In the dry season, only the application of $\mathrm{N}$ in PP provided increments in the production the highest commercial production of tubers being obtained with $189,98 \mathrm{~kg} \mathrm{ha}^{-1}$ of $\mathrm{N}$; In the wet season, the applications of $\mathrm{N}$ should be accomplished in preplanting and in sidedress, with the rate of $255,85 \mathrm{~kg} \mathrm{ha}^{-1}$ of $\mathrm{N}$, being $20 \%$ applied in pre-planting and the remaining in sidedress.
\end{abstract}

Keywords: Solanum tuberosum L, planting seasons, fertilization, chlorophyllometer.

(Recebido para publicação em 30 de outubro de 2007; aceito em 5 de dezembro de 2008) (Received in October 30, 2007; accepted in December 5, 2008)

\begin{abstract}
A batata é uma cultura muito impor tante para o Brasil. No ano de 2007, foram plantados 144 mil ha com a produção de 3,4 milhões de t, alcançando a produtividade média de $23 \mathrm{tha}^{-1}$. Em Minas Gerais foram cultivados, nesse mesmo ano, 40 mil ha e produzidas 1,1 milhão de $t$, o que equivale a cerca de um terço da produção nacional (AGRIANUAL, 2008).

Diferentemente do que ocorre nos países europeus, no Brasil a batata é plantada e colhida o ano todo, nas safras denominadas de seca, águas e inverno. As safra da seca e de inverno são colhidas nos meses de abril a outubro, com baixa fre-
\end{abstract}

qüência e volume de chuva e temperatura amena. A demanda de água pela cultura é complementada pela irrigação. A safra das águas ocorre no período quente e chuvoso quando o excesso de chuva pode lixiviar o adubo nitrogenado. Nesta época ocorrem aumentos da temperatura, fotoperíodo e precipitação pluviométrica. $\mathrm{Na}$ época das águas, o teor de nitrogênio $(\mathrm{N})$ no solo pode decrescer pela ação da água da chuva (Dynia et al., 2006), principalmente na emergência da cultura. Devido às raízes não terem seu sistema radicular desenvolvido, recomenda-se aplicar um terço de $270 \mathrm{~kg} \mathrm{ha}^{-1}$ de nitrato de amônio na batata (Errebhi et al., 1998).
As diferenças de precipitação nas diversas safras precisam ser consideradas no manejo do fertilizante nitrogenado. A quantidade de $\mathrm{N}$ requerida pela cultura, nas diferentes épocas, pode ser diferente em função da sua taxa de absorção e, talvez, sua aplicação deva ser alterada para não ocorrer perda do fertilizante.

Em qualquer época de plantio, uma das maneiras de aumentar a produção da cultura da batata é utilizando-se fertilizantes, principalmente o nitrogenado que deve propiciar a obtenção da produtividade máxima. Para isso é necessário aplicar o fertilizante nitrogenado em

${ }^{1}$ Parte da tese, apresentada pelo primeiro autor, ao curso de pós-graduação em Fitotecnia da UFV, para obtenção do título de doutor. 
época e quantidade apropriadas, reduzindo a poluição ambiental sem acarretar lixiviação de excesso do nitrato e sem prejuízos ao agricultor pelo gasto com o adubo perdido. É sabido que a aplicação excessiva do N pode ocasionar problemas de embonecamento e coraçãooco, como também a sua deficiência, ocasionar pinta preta (Filgueira, 2002).

A adubação nitrogenada é indispensável para obtenção de boas produções e o seu custo é relativamente baixo comparado a outros insumos. As recomendações variam de 70 a $330 \mathrm{~kg} \mathrm{ha}^{-1}$ de $\mathrm{N}$ nos países da Europa e América do Norte (Kolbe \& Beckmann, 1997) e de 60 a $250 \mathrm{~kg} \mathrm{ha}^{-1}$ de $\mathrm{N}$ (Fontes, 1997) nos estados do Centro-Sul do Brasil.

O parcelamento da dose recomendada de $\mathrm{N}$ pode melhorar o manejo de fertilização nitrogenada, sendo essa decisão obtida pela avaliação do estado de $\mathrm{N}$ da batata. Essa avaliação pode ser feita pela análise do teor de $\mathrm{N}$ na matéria seca, como também pela determinação indireta do teor de clorofila (Fontes, 2001). Estudos têm mostrado que o teor de $\mathrm{N}$ na folha correlaciona-se positivamente com a taxa fotossintética da planta, sendo a clorofila envolvida diretamente no processo de fotossíntese (Makino et al., 1994; Vouillot et al., 1998). Com o aparelho portátil, denominado SPAD ou clorofilômetro, que mede a luz na faixa do comprimento de onda de 645 e $663 \mathrm{~nm}$, verifica-se a atividade da clorofila ou o verde da planta (Yadava, 1986). O índice ou valor SPAD é proporcional à quantidade de clorofila presente na folha (Minolta Câmera Co., 1989). Estudos utilizando o SPAD têm demonstrado que o aparelho pode ser útil para avaliar o estado de $\mathrm{N}$ da planta, em diferentes espécies como beterraba (Sexton \& Carroll, 2002), pimentão (Madeira et al., 2003), tomate (Fontes \& Ronchi, 2002; Fontes \& Araújo, 2007), alface (Fontes et al., 1997; León et al., 2007) e batata (Gil, 2001; Gianquinto et al., 2003; Wu et al., 2007).

$\mathrm{O}$ índice SPAD pode ser indicativo da necessidade da aplicação do N, desde que se conheça o nível crítico abaixo do qual a planta estaria deficiente neste elemento, apesar de diversos fatores afetarem o índice SPAD, como as condições edafoclimáticas, cultivar, variações anuais e locais (Bullock \& Anderson, 1998). Considerando a inexistência de dados para batata no Brasil objetivouse estabelecer o nível crítico SPAD no folíolo terminal da quarta folha completamente expandida da batata e determinar as doses ótimas de $\mathrm{N}$ em pré-plantio e em cobertura, em plantios realizados nas épocas da seca e das águas.

\section{MATERIAL E MÉTODOS}

Foram realizados dois experimentos, um em período seco (111 mm de chuva), de 14/05 a 03/09/04, com irrigação suplementar, e outro em período chuvoso (708 mm de chuva), de 01/11/04 a 06/02/05. Os experimentos foram instalados em campo da UFV, a $690 \mathrm{~m}$ de altitude. O solo da área experimental foi classificado como Podzólico Vermelho-Amarelo Câmbico (EMBRAPA, 2006) e continha 1,50 e 2,00 mg kg-1 de N-NO $, 4,52$ e 3,52 dag $\mathrm{kg}^{-1}$ de matéria orgânica, 123 e 54 $\mathrm{mg} \mathrm{dm}^{-3}$ de $\mathrm{P}$ disponível, 153 e 149 de $\mathrm{K}$ $\mathrm{mg} \mathrm{dm}{ }^{-3}$ disponível, 6,57 e $6,27 \mathrm{cmol}_{\mathrm{c}} \mathrm{dm}^{-3}$ de Ca trocável, 0,83 e 0,71 $\mathrm{cmol}_{\mathrm{c}} \mathrm{dm}^{-3} \mathrm{de}$ Mg trocável, 0,00 e $0,00 \mathrm{cmol}_{\mathrm{c}} \mathrm{dm}^{\mathrm{c}} \mathrm{de}^{-3} \mathrm{Al}$ trocável, 28 e $28 \%$ de areia, 61 e $61 \%$ de argila e 11 e $11 \%$ de silte, na camada de 0-20 cm nos experimentos nos períodos seco e chuvoso, respectivamente.

O delineamento experimental foi em blocos casualizados, em parcela subdividida, com quatro repetições. Nas parcelas aplicaram-se as doses de N em préplantio, e nas subparcelas foram aplicadas as doses de $\mathrm{N}$ em cobertura. Os tratamentos consistiram das combinações de cinco doses de nitrogênio $(\mathrm{N})$ em préplantio $\left(0 ; 50 ; 100 ; 200\right.$ e $300 \mathrm{~kg} \mathrm{ha}^{-1} \mathrm{de}$ $\mathrm{N})$ com quatro doses em cobertura $(0$; $100 ; 200$ e $300 \mathrm{~kg} \mathrm{ha}^{-1}$ de N). Foi utilizado o sulfato de amônio como fonte de N.A aplicação das doses de N em pré-plantio foi realizada no sulco de plantio. $\mathrm{O}$ plantio foi efetuado em sulcos com distância entre linhas de $75 \mathrm{~cm}$. As doses em cobertura foram distribuídas nos dois lados das plantas, aos 21 dias após a emergência, realizando-se em seguida a amontoa. Nas subparcelas aplicaram-se doses de $\mathrm{N}$ em cobertura. A parcela mediu 4,5 m x 8,0 m, sendo composta de 6 fileiras de plantas, espaçadas de $0,75 \mathrm{~m}$ entre fileiras e $0,25 \mathrm{~m}$ entre plantas. A subparcela mediu $4,5 \mathrm{~m}$ x 2,0 $\mathrm{m}$.
O solo foi preparado com arado de aiveca e duas passagens de grade niveladora. A adubação com macro e micronutrientes seguiu as recomendações de Fontes (1999). A batata-semente plantada foi de tamanho uniforme, peso médio de $75 \mathrm{~g}$, da cultivar Monalisa. A cultura foi conduzida segundo as recomendações de manejo preconizadas (Fontes, 2005).

A irrigação foi realizada apenas no experimento da época seca, utilizandose o sistema de aspersão. A lâmina de água foi estabelecida a partir da estimativa da evapotranspiração de referência e do coeficiente de cultura (Kc). A estimativa de evapotranspiração de referência foi realizada pelo método de PenmanMonteith, proposto pela FAO (Allen, 1993). O solo foi mantido com a umidade próxima à capacidade de campo.

Aos 21 dias após a emergência, na época do estádio vegetativo, foi determinado o índice SPAD no folíolo terminal da quarta folha completamente expandida, devido ser esta folha recomendada para verificar o estado nutricional da batateira (Fontes, 2005). A medição foi feita com o medidor portátil de clorofila SPAD-502 (Soil-Plant Analysis Development-502), seguindo-se os procedimentos indicados em Fontes \& Araújo (2007).

Uma semana após o total secamento da parte aérea, que ocorreu aos 77 e 70 dias após a completa emergência (98 e 91 dias após o plantio), para a época seca e das águas, respectivamente, os tubérculos foram colhidos e determinadas a produção comercial (sem ataques de pragas, doenças, embonecamento, esverdeamento, dano mecânico, rachadura e maiores que $3,3 \mathrm{~cm}$ de diâmetro longitudinal) e total (comercial e não comercial).

Foi determinado o valor da dose de $\mathrm{N}$ em pré-plantio (PP) que proporcionou a maior produção comercial de tubérculos. Esse valor foi aplicado na equação estabelecida entre os valores do índice SPAD e dose de N em PP para calcular o nível crítico SPAD (Fontes, 2001). Quando a dose de N em PP não foi suficiente para atingir a máxima produção comercial de tubérculos, considerou-se também a dose de $\mathrm{N}$ em cobertura.

Os dados foram submetidos à análise de regressão. Utilizaram-se os programas System Analysis Statistics (SAS) 

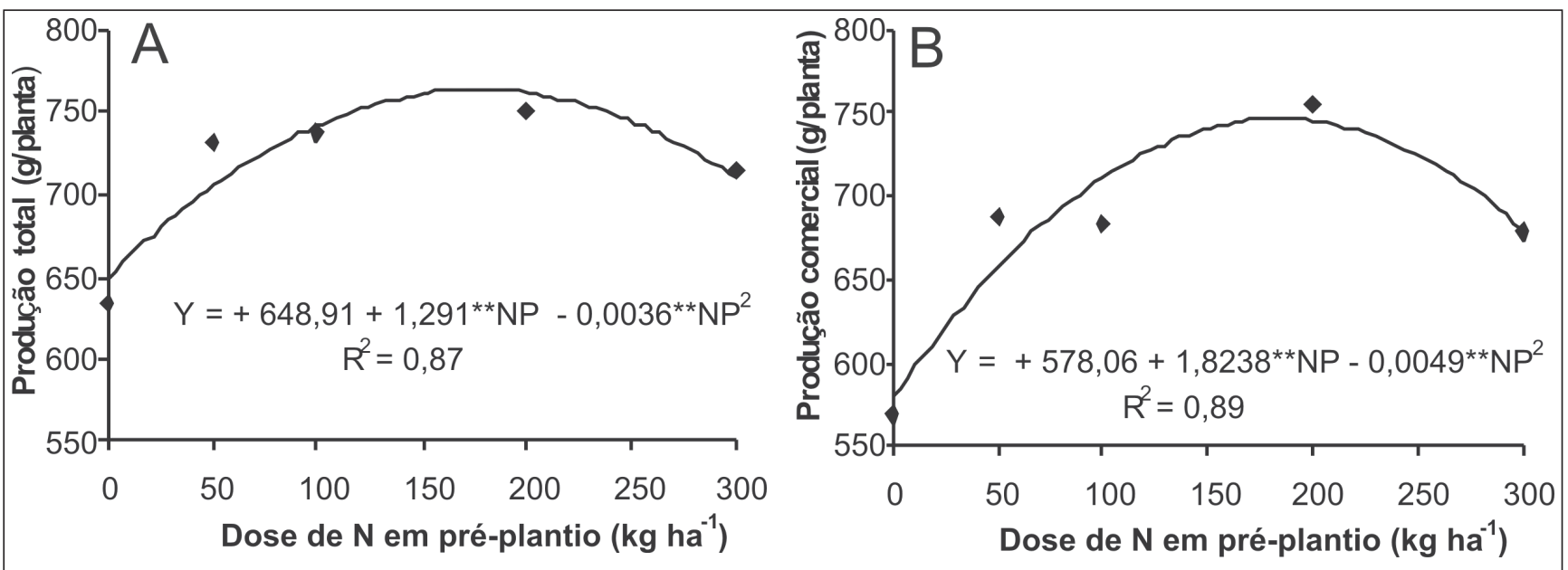

Figura 1. Estimativa da produção total (A) e comercial (B) de tubérculos de batata em função de dose de N aplicada em pré-plantio (NP). Época seca. (estimate of the total (A) and commercial production (B) of potato tubers depending on the rate of applied $\mathrm{N}$ in pre-planting (NP). Dry season). Viçosa, UFV, 2007.

** Significativo estatisticamente pelo teste $\mathrm{t}(\mathrm{p}<0,01)$.

(SAS, 1990) e Sistema para Análises Estatísticas e Genéticas (SAEG) (Ribeiro Júnior, 2001).

\section{RESULTADOS E DISCUSSÃO}

Não houve interação significativa dos fatores doses de $\mathrm{N}$ em PP e doses de $\mathrm{N}$ em cobertura (Figuras 1A e 1B). Somente houve efeito significativo da aplicação de N em PP sobre a produção total e comercial dos tubérculos na época seca.

Por não ter havido efeito da aplicação de $\mathrm{N}$ em cobertura, somente são mostrados os resultados da produção total e comercial de tubérculos em função de doses de N em PP quando utilizou-se a média das doses em cobertura (Figuras 1A e 1B). A produção total de tubérculos aumentou com o aumento na dose de $\mathrm{N}$ em PP até $180,43 \mathrm{~kg} \mathrm{ha}^{-1}$ atingindo 746,65 g/planta (Figura 1A), correspondendo a $39,82 \mathrm{t} \mathrm{ha}^{-1}$. Da mesma forma, a produção comercial de tubérculos aumentou com o aumento na dose de N em PP até 189,98 $\mathrm{kg} \mathrm{ha}^{-1}$ atingindo 747,69 g/planta (Figura 1B), correspondente a $39,88 \mathrm{t} \mathrm{ha}^{-1}$. Na época seca, o N disponível e mineralizável existentes no solo mais a dose de $\mathrm{N}$ adicionada em PP como fertilizante atenderam à demanda da planta, não necessitando de aplicar o $\mathrm{N}$ em cobertura. Isso deve-se, em parte, a não ocorrência de intensa precipitação pluviométrica durante o período experimental não propiciando condições para a lixiviação do fertilizante nitrogenado, conforme verificado por Westermann et al. (1988). Isso mostra que a afirmação de que a aplicação de toda a dose de N em pré-plantio economiza tempo e dinheiro, mas impede adequar a dose durante o ciclo da planta (Olivier et al., 2006) pode não ser verdadeira nesse caso.

O valor de 189,98 $\mathrm{kg} \mathrm{ha}^{-1}$ de N, que propiciou a máxima produção comercial de tubérculos, está dentro das faixas de fertilização de 70 a $330 \mathrm{~kg} \mathrm{ha}^{-1}$ de $\mathrm{N}$ encontrada por Kolbe \& Beckmann (1997) e de 60 a $250 \mathrm{~kg} \mathrm{ha}^{-1}$ de $\mathrm{N}$ citadas por Fontes (1997). Andreu (2005), no RS, verificou produtividade média de 18,43 e $11,29 \mathrm{tha}^{-1}$ com a dose de $100 \mathrm{~kg} \mathrm{ha}^{-1}$ de N. Gil (2001), em Viçosa (MG), emépoca seca, verificou que com o aumento das doses de N em PP aumentou de forma quadrática a resposta da produtividade comercial de tubérculos que atingiu o maior valor, $24,75 \mathrm{tha}^{-1}$, com 158,46 $\mathrm{kg} \mathrm{ha}^{-1}$ de N aplicado em PP e $360 \mathrm{~kg} \mathrm{ha}^{-1}$ de $\mathrm{N}$ em cobertura.

Por outro lado, na época das águas, ocorreu efeito significativo da aplicação de N em PP, e em cobertura sobre a produção total e comercial dos tubérculos. Os valores destas variáveis, estimados com base na dose $50 \mathrm{~kg} \mathrm{ha}^{-1} \mathrm{de} \mathrm{N} \mathrm{em} \mathrm{PP,}$ propiciaram a maior produção entre as demais aplicadas em pré-plantio (Figuras $2 \mathrm{~A}$ e $2 \mathrm{~B}$ ). Também não ocorreu interação significativa entre os fatores doses de $\mathrm{N}$ em PP e doses de $\mathrm{N}$ em cobertura, quando comparado com a época seca.

A produção comercial de tubérculos aumentou com o aumento na dose de $\mathrm{N}$ em cobertura até $205,85 \mathrm{~kg} \mathrm{ha}^{-1}$ atingindo 833,66 g/planta, correspondente a 44,46 tha $^{-1}$ (Figura 2B). Comparando os resultado de produtividades obtidos tanto na época seca quanto das águas com a produtividade média de MG 27,50 $\mathrm{t} \mathrm{ha}^{-1}$, em 2007 (AGRIANUAL, 2008), verifica-se que os valores encontrados nestes experimentos foram expressivamente maiores.

$\mathrm{Na}$ época das águas, a precipitação verificada nas primeiras quatro semanas após a emergência das plantas foi $177 \%$ maior do que no período seco, podendo ter provocado redução na disponibilidade do N colocado em PP, ocasionando menor eficiência do uso do $\mathrm{Ne}$, conseqüentemente, necessidade de aplicação de $\mathrm{N}$ em cobertura para maior produção de tubérculos comerciais. Ademais, no estádio inicial, a batata absorve pequena quantidade de $\mathrm{N}$ (Nunes $e t$ al., 2006) que pode tornar-se disponível para ser lixiviado.

É comum a recomendação de aplicar baixa dose de $\mathrm{N}$ em $\mathrm{PP}$, pois o $\mathrm{N}$ do solo é liberado para a planta (Walther et al., 1996) e há a probabilidade de perda de $\mathrm{N}$ por excesso de chuva (Fontes \& Araújo, 2007). O restante da dose deve ser 


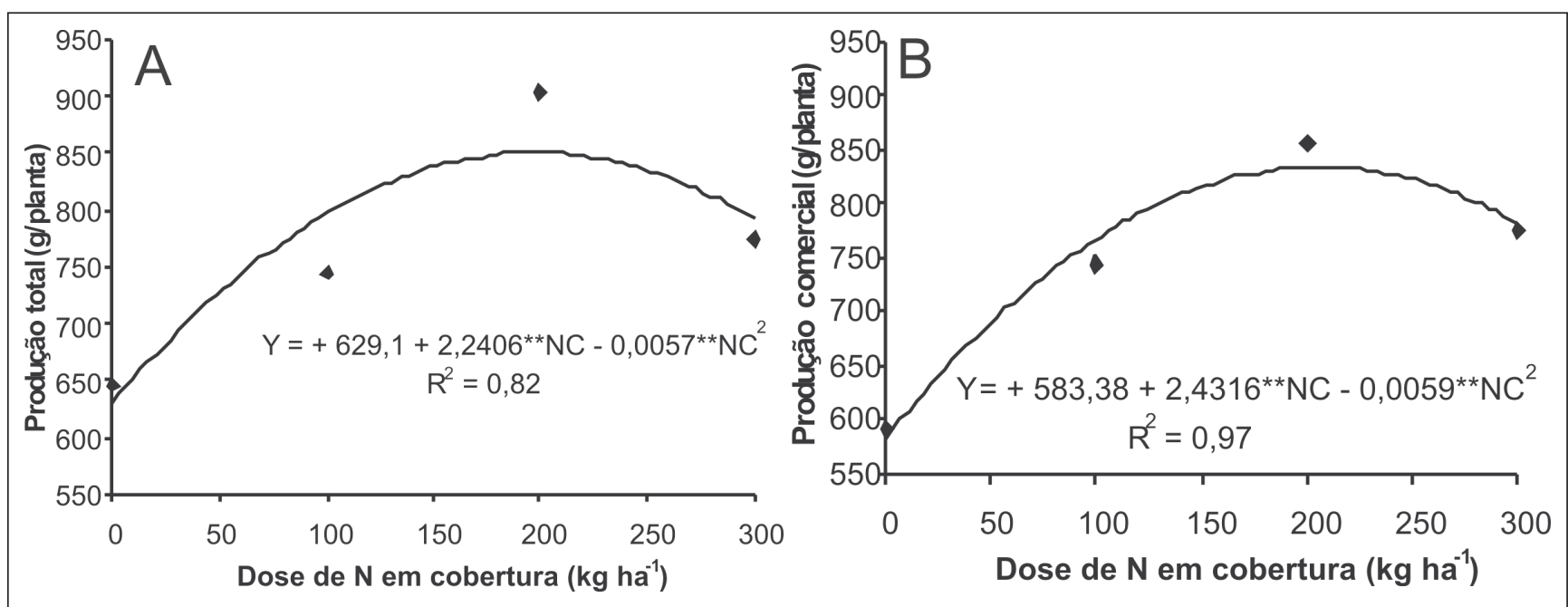

Figura 2. Estimativa da produção total (A) e comercial (B) de tubérculos de batata em função de dose de N aplicada em cobertura (NC), no tratamento que recebeu $50 \mathrm{~kg} \mathrm{ha}^{-1} \mathrm{de} \mathrm{N}$ em pré-plantio. Época das águas. (estimate of the total (A) and commercial production (B) of potato tubers depending on the rate of applied $\mathrm{N}$ in sidedress (NC), in the treatment that received $50 \mathrm{~kg} \mathrm{ha}^{-1}$ of $\mathrm{N}$ in pré-planting. Wet season). Viçosa, UFV, 2007. ** Significativo estatisticamente pelo teste $\mathrm{t}(\mathrm{p}<0,01)$.

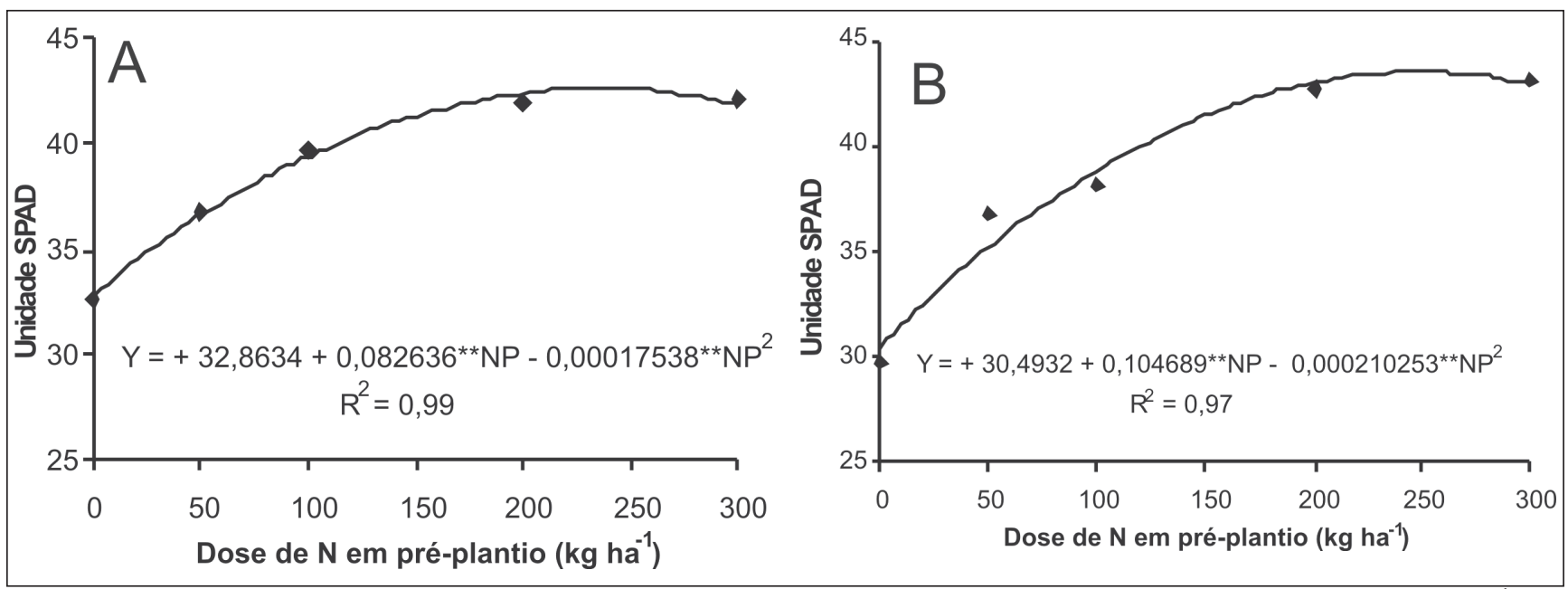

Figura 3. Estimativa do índice SPAD na quarta folha de batata, aos 21 DAE, em função de dose de N aplicada em pré-plantio (NP). Época seca (A) e das águas (B). (Estimate of the index SPAD on the fourth leaves of potato plants, $21 \mathrm{DAE}$, depending on the rate of applied $\mathrm{N}$ in pre-planting (NP). Dry (A) and wet season (B). Viçosa, UFV, 2007.

** Significativo estatisticamente pelo teste $\mathrm{t}(\mathrm{p}<0,01)$.

colocada em cobertura (Westermann \& Sojka, 1996), minimizando as possíveis perdas de N. Essa recomendação foi válida para o plantio realizado na época das águas. Entretanto, o parcelamento do $\mathrm{N}$ nem sempre eleva a absorção do $\mathrm{N}$ e o rendimento da batata (Hong et al., 2003), conforme foi verificado no experimento da seca.

No trabalho de Gil (2001), na ausência da adubação em cobertura, a produtividade estimada reduziria para 21,33 t ha $^{-1}$, portanto redução de $14 \%$. O efeito da adubação em cobertura, mesmo tendo baixa eficiência agronômica, $9,5 \mathrm{~kg}$ $\mathrm{kg}^{-1}$, pode ter sido devido à competição com tiririca e o aparecimento de doença de solo, no final do ciclo, que podem ter impedido as raízes de explorarem grande área de solo, limitando a absorção de $\mathrm{N}$ do solo e levando à necessidade de adubar com $\mathrm{N}$ em cobertura.

$O$ valor SPAD, na época seca, foi influenciado pela aplicação do $\mathrm{N}$ em préplantio, quando a cobertura com $\mathrm{N}$ ainda não havia sido feita. $\mathrm{O}$ valor SPAD aumentou com o aumento na dose de $\mathrm{N}$ em pré-plantio ( $\mathrm{N}$ em $\mathrm{PP}$ ) até alcançar o valor máximo de 42,6 unidades (Figura $3 \mathrm{~A}$ ) e o valor crítico calculado foi 42,2 , associado à dose de N em PP de 189,98 $\mathrm{kg} \mathrm{ha}^{-1}$. Essa dose está de acordo com os obtidos para a máxima produção comercial de tubérculos.

Na época das águas, o valor do índice SPAD foi também influenciado pela aplicação do N em PP. A relação entre os valores SPAD e doses de N em PP apresentou comportamento quadrático (Figura 3B) e o valor crítico calculado foi 35,2 associado à dose $50 \mathrm{~kg} \mathrm{ha}^{-1} \mathrm{de} \mathrm{N} \mathrm{em}$ PP. Essa dose não foi suficiente para obtenção da máxima produção comercial sendo necessário aplicar 205,85 kg ha $^{-1}$ de $\mathrm{N}$ em cobertura. Fica evidente a 
importância do uso do SPAD, devido ajudar a encontrar doses diferentes de $\mathrm{N}$, como 189,98 $\mathrm{kg} \mathrm{ha}^{-1} \mathrm{de} \mathrm{Ne} 255,85 \mathrm{~kg}$ ha $^{-1}$ de N, para produção comercial de tubérculos (Figuras 1B e 2B), nas épocas seca e das águas, para manejar corretamente a adubação da batata.

Os resultados obtidos nesse experimento foram diferentes dos obtidos por Rodrigues (2004). O valor crítico SPAD encontrado por esse autor foi de 52,8 com a dose de $237,50 \mathrm{~kg} \mathrm{ha}^{-1}$ de N. O autor realizou o experimento em Portugal, em época quente e seca, no período do verão, em diferente comprimento do dia, em solo arenoso e utilizou a cultivar Desirée, com exigência muito semelhante com a Monalisa. Esses fatores podem ter contribuído para a diferença nos resultados obtidos nesses experimentos.

Além disso, Gil (2001), em experimento feito na época seca, encontrou o valor crítico de 45,3 associado à dose de $158,46 \mathrm{~kg} \mathrm{ha}^{-1}$ de N em PP que propiciou a maior produção comercial (594 g/planta), equivalendo a $\left.24,75 \mathrm{t} \mathrm{ha}^{-1}\right) . \mathrm{O}$ ano (2000), a época de amostragem (23 dias após a emergência), o teor de nitrato no solo (30,24 mg kg-1), a matéria orgânica no solo e a origem da batata-semente (não fornecidos pela pesquisadora) podem ter afetado o padrão de desenvolvimento da cor verde da folha, conseqüentemente alteração no valor do índice SPAD, propiciando diferença de produtividade comercial entre os experimentos.

Finalmente, vale ressaltar, que vários fatores podem afetar o valor de SPAD, entre os quais posição de leitura na folha, incluindo ou não a nervura (Arregui et al., 2000), genótipo, estádio de crescimento da planta, idade da folha, temperaturas extremas, luminosidade no momento da leitura, época do ano e outros (Fontes \& Araújo, 2007). Além dos fatores que influenciam o valor da leitura SPAD, há influencia marcante do procedimento adotado para os cálculos da dose ótima de $\mathrm{N}$ (Fontes et al., 2005) e do nível crítico (Fontes \& Ronchi, 2002) e isso também pode ter contribuído para essas diferenças obtidas. Mas, os dados obtidos podem ser úteis para a região de Viçosa, especificamente para a cultivar Monalisa, em solo Podzólico Vermelho Amarelo-Câmbico, nas épocas seca e das águas.
$\mathrm{Na}$ época seca, somente a aplicação de $\mathrm{N}$ em PP proporcionou incrementos na produção sendo a máxima produção comercial de tubérculos obtidos com $189,98 \mathrm{~kg} \mathrm{ha}^{-1} \mathrm{de} \mathrm{N}$; na época das águas, devem ser realizadas as aplicações de $\mathrm{N}$ em PP e em cobertura, com a dose 255,85 $\mathrm{kg} \mathrm{ha}^{-1}$ de N, sendo $20 \%$ aplicada em pré-plantio e o restante em cobertura antes da amontoa.

O nível crítico SPAD é 42,2 e 35,2, nas épocas seca e das águas, respectivamente, para a região de Viçosa e cultivar Monalisa.

\section{AGRADECIMENTOS}

Ao CNPq pela concessão de bolsas de pós-graduação e de produtividade em pesquisa, à FAPEMIG por recursos financeiros e a UFV pela estrutura física e profissional.

\section{REFERÊNCIAS}

AGRIANUAL. 2008. Anuário da Agricultura Brasileira. $13^{a}$ edição. FNP Consultoria \& Agroinformativos. 502p.

ALLEN RG. 1993. New approaches to estimating crop evapotranspiration. Acta Horticulturae 335: 287-293.

ANDREU MA. 2005. Associação entre características agronômicas da batata nos plantios de primavera e outono no Rio Grande do Sul. Ciência Agrotecnica 29: 925-929.

ARREGUI LM; MERINA M; MINGOCASTEL AM. 2000. Aplicacion del medidor portatil de clorofila em los programas de fertilizacion nitrogenada em patata de siembra. Actas Del Congresso Iberoamericano de Investigación y Desarrolo em Patata, Vitória-Gasteis. 157170 .

BULLOCK DG; ANDERSON DS. 1999. Evaluation of the Minolta SPAD-502 chlorophyll meter for nitrogen management in corn. Journal of Plant Nutrition 21: 741-755.

DYNIA JF; SOUZA MD; BOEIRA RC. 2006. Lixiviação de nitrato em latossolo cultivado com milho após aplicações sucessivas de lodo de esgoto. Pesquisa Agropecuária Brasileira 41: 885-862.

EMBRAPA. 2006. Centro Nacional de Pesquisa de Solos (Rio de janeiro, RJ) Sistema brasileiro de classificação de solos - Brasília: Embrapa. Produção de informação; Rio de janeiro: Embrapa. Solos. 306p.

ERREBHI M; ROSEN CJ; GUPTA SC; BIRONG DE. 1998. Potato yield response and nitrate leaching as influenced by nitrogen management. Agronomy Journal 90: 1015.
FILGUEIRA FAR, 2002. Novo Manual de Olericultura: Agrotecnologia moderna na produção e comercialização de hortaliças. Viçosa: Universidade Federal de Viçosa. $402 \mathrm{p}$.

FONTES PCR. 1997. Preparo do solo, nutrição mineral e adubação da batateira. Viçosa: Universidade Federal de Viçosa. 42p.

FONTES PCR. Batata. In: RIBEIRO AC; GUIMARÃES PTG; ALVAREZ VVH. 1999. Recomendações para o uso de corretivos e fertilizantes em Minas Gerais $5^{a}$ Aproximação. - Viçosa: UFV. 359p.

FONTES PCR. 2001. Diagnóstico do estado nutricional das plantas. Viçosa: Universidade Federal de Viçosa. 122p.

FONTES PCR. 2005. Olericultura: teoria e prática. Viçosa: Universidade Federal de Viçosa. 486p.

FONTES PCR; ARAÚJO C. 2007. Adubação nitrogenada de hortaliças - princípios e práticas com o tomateiro. Viçosa: Universidade Federal de Viçosa. 148p.

FONTES PCR; PEREIRA PRG; CONDE RM. 1997. Critical chlorophyll, total N, and $\mathrm{NO}_{3}{ }^{-} \mathrm{N}$ in leaves associated to maximum lettuce yield. Journal of Plant Nutrition 20: 1061-1068.

FONTES PCR; RONCHI CP. 2002. Critical values of nitrogen indices in tomato plants grown in soil and nutrient solution determined by different statistical procedures. Pesquisa Agropecuária Brasileira 37: 1421-1429.

GIANQUINTO G; SAMBO P; BONA S. 2003. The use of SPAD-502 chlorophyll meter for dynamically optimizing the nitrogen supply in potato crop: A methodological Approach. Acta Horticulturae 607.

GIL PT. 2001. Índices e eficiência de utilização de nitrogênio pela batata influenciados por doses de nitrogênio em pré-plantio e em cobertura. Viçosa: Universidade Federal de Viçosa. 81p. (Tese mestrado).

HONG L; PARENT LE; KARAM A; TREMBLAY C. 2003. Efficiency of soil and fertilizer of a sod-potato system in the humid, acid and cool environment. Plant Soil 251: 23-26.

KOEPPEN W. 1948. Climatologia. Tradução: Pedro R. H. Perez. Buenos Aires, Gráfica Panamericana, 478p.

KOLBE H; BECKMANN SE. 1997. Development, growth and chemical composition of the potato crop (Solanum tuberosum L.). I. leaf and stem. Potato Research 40: 111-129.

LEÓN AP; VIÑA SZ; FREZZA D; CHAVES A; CHIESA A. 2007. Communications in soil science and plant analysis 38: 2877-2885.

MADEIRA AC; FERREIRA A; VARENNES A; VIEIRA MI. 2003. SPAD meter versus tristimulus colorimeter to estimate chlorophyll content and leaf color in sweet pepper. Communications in Soil Science and Plant Analysis 34: 2461-2470.

MAKINO A; NAKANO H; MAE T. 1994. Responses of ribulose-1, 5-bisphosphate carboxylase, cytochrome $\mathrm{f}$, and sucrose synthesis enzymes in rice leaves to leaf nitrogen and their relationships to photosynthesis. Plant Physiology 105: 173-179. 
MINOLTA CAMERA Co. 1989. Manual for chlorophyll meter SPAD-502. Minolta Camera Co., Ltd., Japan. 22p.

NUNES JCS; FONTES PCR; ARAÚJO EF; SEDIYAMA C. 2006. Potato plant growth and macronutrients uptake as affected by soil tillage and irrigation systems. Pesquisa Agropecuária Brasileira 4: 1787-1792.

OLIVIER M; GOFFART JP; LEDENT JF. 2006. Threshold value for chlorophyll meter as decision tool for nitrogen management of potato. Agronomy Journal 98: 496-506.

RIBEIRO JÚNIOR JI. 2001. Análises estatísticas no SAEG - Viçosa: Universidade Federal de Viçosa. 301p.

RODRIGUES MA. 2004. Establishment of continuous critical levels for indices of plant and presidedress soil nitrogen status in the potato crop. Communications in Soil Science and Plant Analysis 35: 2067-2085.
SAS INSTITUTE INC. 1990. SAS/STAT User's Guide. Version 6, 4⿳亠丷厂 ed., volume 02, Cary, NC: SAS Institute Inc.

SEXTON P; CARROLL J. 2002. Comparison of SPAD chlorophyll meter readings vs. petiole nitrate concentration in sugar beet. Journal of Plant Nutrition 25: 1975-1986.

VOS J; BOM M. 1993. Hand-held chlorophyll meter: a promising tool to assess the $\mathrm{N}$ status of potato foliage. Potato Research 36: 301-308.

VOUILLOT MO; HUET P; BOISSARD P. 1998. Early detection of $\mathrm{N}$ deficiency in wheat crop using physiological and radiometric methods. Agronomie 18: 117130.

WALTHER U; SCHUBIGER FX; JAGGLI F. 1996. N-Aufnahme durch Kartoffeln und Nmin-Gehalte des Bodens. Agrarforschung 3: 61-64.
WESTERMANN DT; KLEINKOPF GE.; PORTER LK. 1988. Nitrogen fertilizer efficiencies on potatoes. American Potato Journal 65: 377-386.

WESTERMANN DT; SOJKA RE. 1996. Tillage and nitrogen placement effects on nutrient uptake by potato. Soil Science Society American Journal 60: 1448-1453.

WU J; WANG D; ROSEN CJ; BAUER ME. 2007. Comparison of petiole nitrate concentration, SPAD chlorophyll readings, and QuickBird satellite imagery in detecting nitrogen status of potato canopies. Field Crops Research 101: 96-103.

YADAVA UL. 1986. A rapid and nondestructive method to determine chlorophyll in intact leaves. Hortscience 21: 1449-1450. 